\title{
Technè
}

La science au service de l'histoire de l'art et de la préservation des biens culturels

45 | 2017

Bronzes grecs et romains : études récentes sur la statuaire antique

\section{Le dédicant Atespatus : un nom assuré}

The dedicator Atespatus: an attested name

\section{Monique Dondin-Payre}

\section{(2) OpenEdition}

1 Journals

\section{Édition électronique}

URL : http://journals.openedition.org/techne/1322

DOI : 10.4000/techne.1322

ISSN : 2534-5168

Éditeur

C2RMF

\section{Édition imprimée}

Date de publication : 1 mai 2017

Pagination : 96-97

ISBN : 978-2-7118-6408-9

ISSN : 1254-7867

Référence électronique

Monique Dondin-Payre, «Le dédicant Atespatus : un nom assuré », Technè [En ligne], 45 | 2017, mis en ligne le 19 décembre 2019, consulté le 27 juillet 2020. URL : http://journals.openedition.org/techne/ 1322 ; DOI : https://doi.org/10.4000/techne.1322

\section{(c) (i) (9)}

La revue Technè. La science au service de l'histoire de l'art et de la préservation des biens culturels est mise à disposition selon les termes de la Licence Creative Commons Attribution - Pas d'Utilisation Commerciale - Pas de Modification 4.0 International. 


\section{Le dédicant Atespatus : un nom assuré}

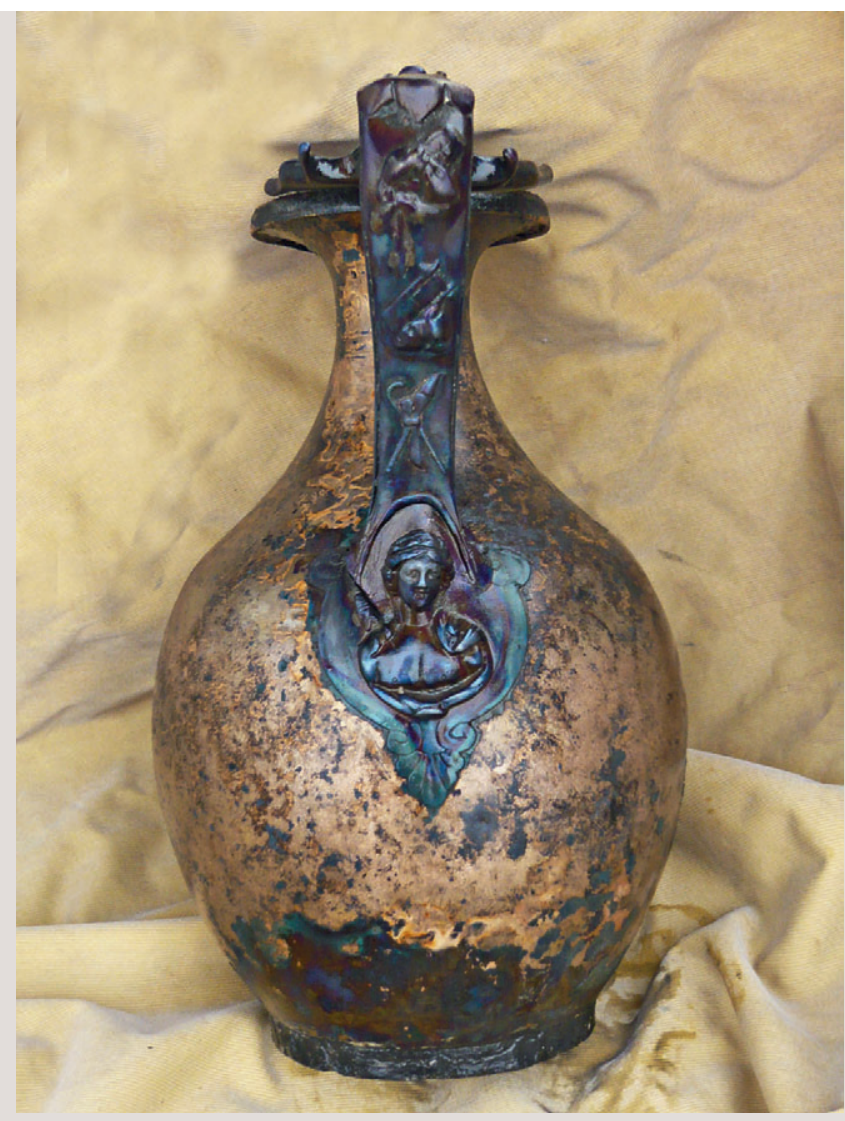

Fig. 1. Vase de Saint-Ambroix-sur-Arnon. @ C. Cribellier.

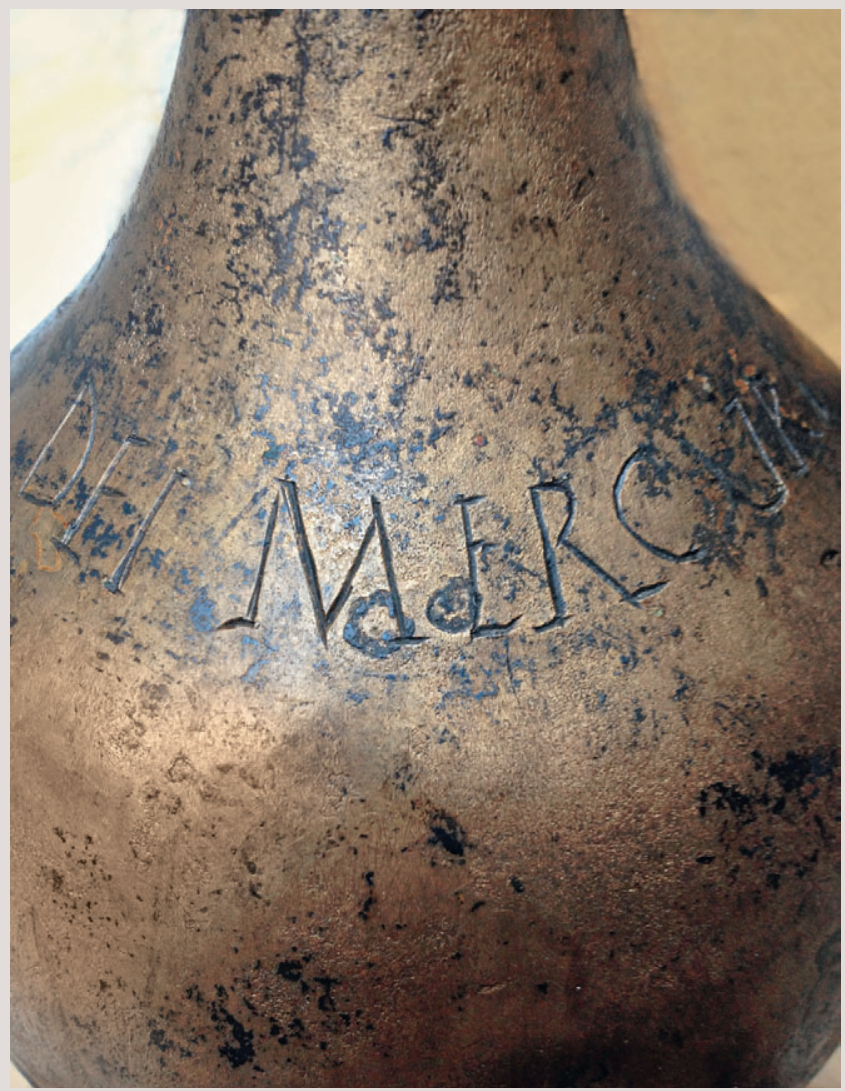

Fig. 2. Détail du nom « Mercuri ». () C. Cribellier. 


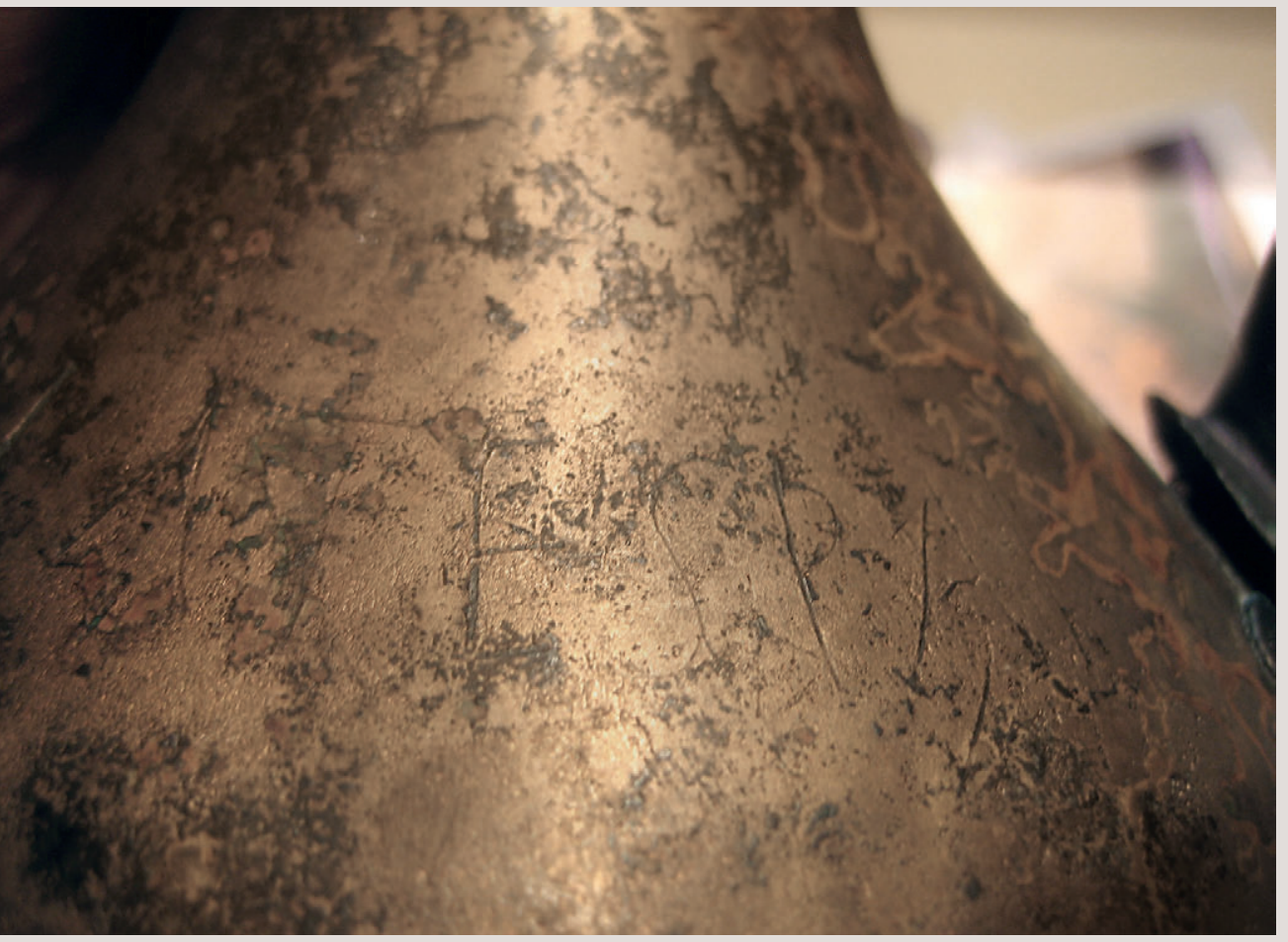

Fig. 3. Détail du nom «Atespatus ». (C) B. Bertin.

\section{Notes}

\section{CIL XIII, 1366}

2. Province d'Aquitaine, à la limite entre les départements du Cher et de l'Indre, région Centre. Cribellier, 2014, p. 52.

3. Le S final a disparu, parce qu'il était trop superficiellement marqué, ou parce que, trop près de l'anse, il a été effacé par sa soudure ou par la rouille. Voir DondinPayre, "Les vases du sanctuaire de La Vallée de Saint-Ambroix », ibid., p. 80.

\section{Bibliographie}

CIL XIII : Corpus Inscriptionum Latinarum. Inscriptiones trium Galliarum et Germaniarum Latinae, O. Hirschfeld (éd.), Berlin, 1899.

Cribellier C., 2014, « Le sanctuaire de La Vallée à Saint-Ambroix (Cher) » dans Exp. Argentomagus, p. 52.

Dondin-Payre M., 2014, « Les vases du sanctuaire de La Vallée de SaintAmbroix » dans Exp. Argentomagus, p. 80.

Exp. Argentomagus, 2014 : Dieux merci! Sanctuaires, dévots et offrandes en Gaule romaine [Exposition Saint-Marcel,

Musée d'Argentomagus, Argenton, 27 juin-7 décembre 2014, Fauduet I. (éd.)].

\section{Notes}

1. Sur le rôle de Prosper Mérimée, voir Héron de Villefosse, 1907, p. 8-9. Sur les avis opposés des spécialistes, voir par exemple Bartman, 1999, p. 3, 195-196 (modernes) ; Lahusen, Formigli, 2001, p. 70-71 (antiques).

2. Paris, musée du Louvre, département des Antiquités grecques, étrusques et romaines, Br 28 (Livie), Br 29 (Auguste) ; H. bustes $19 \mathrm{~cm}$ et $18,5 \mathrm{~cm}$; H. bases $3 \mathrm{~cm}$. Restauration 2005-2006 : A. Conin, J. Dupin, Frœhner, 1873 ; De Ridder, 1913, p. 11, $\mathrm{n}^{\text {os } 28-29,}$ pl. 5 ; Kersauson (de), 1986, $n^{\text {os }} 41-42$, p. 94-97 ; Bartman, 1999, p. 3, 195-196 ; Lahusen, Formigli, 2001, $\mathrm{n}^{\text {os }} 25-26$, p. 70-73, 360-363, 462, 466, 467, 472, 473 ; Dahmen, 2001, n ${ }^{\text {os }} 32-33$, p. 23-26, 53, 155, 156 ; Descamps, 2007 ; 2008 ; Szewczyk, 2014 .

3. Près de Moulin (Allier, France), CAG 03, 1989, n²60, p. 124. Le ruisseau correspond à La Sonnante : Letterlé, 2004.

4. Rolley, 1979, p. 16 ; AvisseauBroustet, 2002.

5. Acte notarié du 29 mai 1816. Bertrand, 1868-1869. Les bustes furent vendus à Pierre Saulnier, fils de la fermière des Guillemins, alors clerc de notaire à Moulins, puis cédés au propriétaire des lieux M. Girodet et restèrent dans sa famille plus de cinquante ans avant d'être vendus aux antiquaires parisiens Rollin et Feuardent (Frœhner 1973, p. 2), puis au Louvre en août 1868 avec l'accord de Napoléon III (n ${ }^{\text {os }}$ d'entrée NIII 3253 et NIII 3254).

6. Les yeux gauches ont été restaurés avant l'entrée des bustes au Louvre en septembre 1868 : Frohner, 1873, p. 5.

7. Respectivement $\mathrm{Br} 21$ et $\mathrm{Br} 42$.

8. Robbiola, Hurtel, 1995. L'historique des œuvres est inexact.

9. CIL XIII 1366. Sur le caractère honorifique des inscriptions, plutôt que témoignage d'une forme de culte impérial, voir Fishwick, 1991, p. 535 n. 363.

10. La hauteur depuis le menton jusqu'au sommet du crâne est de $10 \mathrm{~cm}$ pour Livie et de $11,5 \mathrm{~cm}$ pour Auguste.

11. Pour le type Louvre-Forbes, voir au musée du Louvre le portrait d'Auguste Ma 1280, possiblement daté de 29 av. J.-C. (Szewczyk, 2014, n 32, p. 78).

12. Le premier témoignage de cette mode capillaire se trouve au revers d'un aureus de Marc Antoine, daté des années 40-39 avant J.-C., sur lequel on identifie le profil d'Octavia. Berlin, Münzkabinett, Bartman, 1999, p. 59, fig. 47.

13. Buste éponyme du type dit de Marbury Hall, conservé au musée de Liverpool, inv. 1988.116, Bartman, 1999, p. 64-67, 161-162, fig. 52-54, 143.

14. Bartman, 1999, p. 67, 190, fig. 55.

15. D'après le buste éponyme découvert à Arsinoé et conservé à la Ny Carlsberg Glyptotek de Copenhague, inv. n ${ }^{\circ} 1444$, Johansen, 1994, n 36, p. 96-97 (pas de mèches parotides) ; Bartman, 1999, p. 4-5, 74- 77, 174-175.

16. Paris, musée du Louvre, Département des Antiquités grecques, étrusques et romaines, Ma 1233.

17. Ny Carlsberg Glyptotek, inv. $\mathrm{n}^{\circ} 748$, Johansen, 1994, n 35, p. 94-95 (mais 